\title{
Microstructure, Phase Transformations, and Properties of Hot-Extruded Ni-Rich NiTi Shape Memory Alloy
}

\author{
Z. Lekston, M. Zubko, K. Prusik, and D. Stróż
}

\author{
(Submitted October 14, 2013; in revised form May 4, 2014; published online May 23, 2014)
}

\begin{abstract}
Processing of NiTi shape memory alloys strongly influences their microstructure, phase transformations, mechanical, and shape memory properties. Hot forging, hot swaging, or hot rolling are efficient techniques for obtaining the desired shape, but during multiple operations the material must be heated and worked in the temperature range from 700 to $900{ }^{\circ} \mathrm{C}$. During these processes, intense oxidation takes place. In order to reduce it, the hot-pack working is applied. The hot extrusion is more effective for reduction of ingot, billet, and rod diameters than hot forging, hot swaging, or hot rolling. Also, during hot extrusion the material surface undergoes considerably less oxidation. In the present work, results of the characterization by differential scanning calorimetry, low-temperature $x$-ray powder diffraction, and three-point bending and free recovery ASTM F2082-06 tests of the samples after hot direct extrusion and heat treatment are presented. The obtained alloy after hot direct extrusion exhibits desired shape memory effect. The phase transformations during cooling and heating cycle occur with the presence of the $R$ phase. The range of the characteristic temperatures for the obtained material gives possibility for further medical applications. After annealing at 400 and $500{ }^{\circ} \mathrm{C}$, the characteristic temperatures shift to higher values.
\end{abstract}

Keywords hot direct extrusion, LTXRD, NiTi shape memory alloy, one-way shape memory effect, phase transitions

\section{Introduction}

NiTi alloys with near-equiatomic composition, commonly known as Nitinol alloys, exhibit shape memory and superelastic effects (Ref 1,2). They are also materials used in the medical applications (Ref 3-10). For their wider usage development of easier and more effective ways of metalworking is necessary. Melting, casting, metalworking, and heat treatments of NiTi shape memory alloys strongly influence their microstructure, phase transformations, mechanical, and shape memory properties (Ref 11, 12). Due to the fact that molten titanium is highly reactive, the NiTi alloys must be melted in high vacuum or in an inert gas atmosphere (Ref 12, 13). Vacuum induction melting (VIM) and vacuum arc remelting (VAR) are commonly used for production of NiTi shape memory alloys. In VIM process usually high-purity, high-density, and low-porosity graphite crucibles and molds are used (Ref 11, 13-15). CaO crucibles are preferred for extenuation of carbon content in NiTi melts. Unfortunately, such crucibles are not resistant to thermal shock and often crack during

\footnotetext{
This article is an invited paper selected from presentations at the
International Conference on Shape Memory and Superelastic

This article is an invited paper selected from presentations at the
International Conference on Shape Memory and Superelastic Technologies 2013, held May 20-24, 2013, in Prague, Czech Republic, and has been expanded from the original presentation.

Z. Lekston, M. Zubko, K. Prusik, and D. Stróż, Institute of Materials Science, University of Silesia, ul. 75 Pułku Piechoty 1a, 41-500 Chorzow, Poland. Contact e-mails: zdzislaw.lekston@us.edu.pl, maciej.zubko@us.edu.pl, krystian.prusik@us.edu.pl, and danuta.stroz@ us.edu.pl.
}

melting process (Ref 13). The main advantage of VIM method is the obtained homogeneity of chemical composition of the ingot, because electrical eddy currents and electrodynamic forces induced in the graphite crucible and in the metallic charges result in the whirling and mixing of the melt (Ref 12, 16). High-quality NiTi alloys can be produced by VAR method, however, multiple re-melts are required to achieve acceptable homogeneity (Ref 16) The larger size ingots in the industrial production of NiTi shape memory alloys are routinely produced using the VIM/VAR double-melt process (Ref 16). After casting and homogenization heat treatment, the ingots must be hot worked to semi-finished products. Depending on the final product shape, various techniques such as press forging, rotary forging, extrusion, swaging, bar rolling, and sheet rolling, wire drawing may be used in the hot working stage (Ref 11, 13). Following hot working, Nitinol alloys are cold worked and heat-treated to obtain final dimension and shape and with desired physical and mechanical properties. During cold drawing of wires, multiple reductions of diameters and frequent inter-pass annealing at $600-800{ }^{\circ} \mathrm{C}$ is require (Ref 16).

During the hot working intense, oxidation of the material surface takes place. To prevent oxidation, the NiTi billets have been canned in mild steel for hot working. This technique was used for swaging, forging, and extrusion (Ref 13). The direct and indirect extrusion are applied to production of tubes and hot working of ingots and billets (Ref 17, 18). Direct extrusion of NiTi ingots could be performed without protective sleeve at temperatures of $950-1050{ }^{\circ} \mathrm{C}$ with the extrusion ratios of $11: 1$ and 6:1 (Ref 18). During indirect extrusion, the NiTi billets were canned into a protective $\mathrm{Cu}$ alloy and processed at temperature of about $900{ }^{\circ} \mathrm{C}$ with extrusion ratios from $27: 1$ to 18:1 (Ref 19). The wire of functionally graded TiNi shape memory alloy which varies in Ti-Ni compositions along the wire axis was laboratory fabricated by new pulse current pressure sintering and the subsequent hot extrusion process. A billet of $5 \mathrm{~mm}$ in diameter was hot extruded into a wire of 
$2 \mathrm{~mm}$ in diameter. Hot extrusion process was carried out at $800{ }^{\circ} \mathrm{C}$ with extrusion ratio 6.25 (Ref 20). Recently, the laboratory direct extrusion test was performed to provide the cold work of the $\mathrm{Cu}-\mathrm{Zn}-\mathrm{Al}$ shape memory alloy in the as cast rod condition. The diameter was reduced from 12 to $10 \mathrm{~mm}$ at extrusion ratio 1.44 (Ref 21$)$.

In the present studies, the shape memory alloy with nominal composition $\mathrm{Ni}_{50.8} \mathrm{Ti}_{49.2}$ obtained by conventional VIM technique is presented. The alloy has promising characteristics for medical application. The hot direct extrusion without protective sleeve was applied for processing of the studied material. The aim of this study was to examine the possibility of using hot extrusion for rough metalworking of NiTi ingots obtained by VIM method at the laboratory scale and to determine the phase composition, temperature, and the sequence of phase transitions and to investigate the shape memory effect. In this work, the characteristic temperatures of phase transformations hysteresis and oneway shape memory effect obtained by differential scanning calorimetry (DSC) method, low-temperature x-ray powder diffraction (LTXRD) technique, and three-point bending and

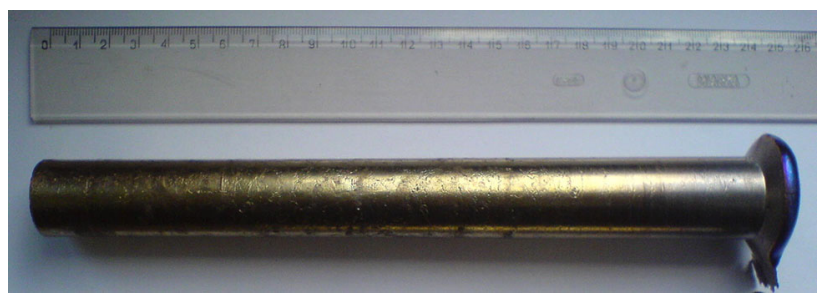

Fig. 1 The $900 \mathrm{~g}$ NiTi ingot obtained after vacuum induction melting

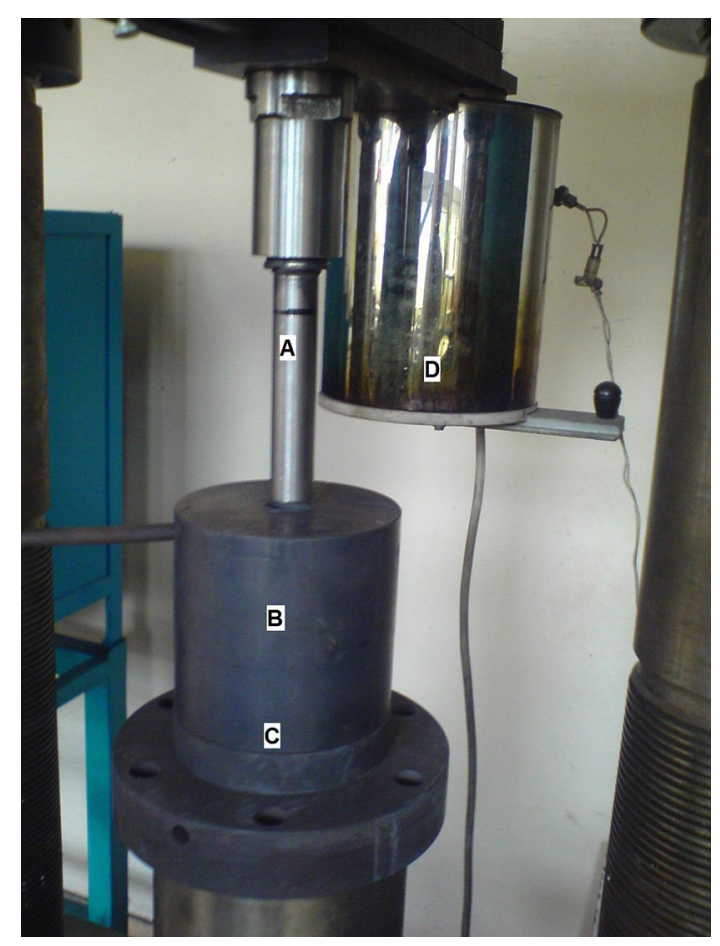

Fig. 2 Laboratory press $(1000 \mathrm{kN})$ equipped with attachment for hot direct extrusion. By $A$ the steel ram is marked, $B$ is the container, $C$ is the mounting position of extrusion die inside in container. By $D$ electrical furnace for heating samples up to about $1100{ }^{\circ} \mathrm{C}$ is marked free recovery ASTM F2082-06 (TPBFR) tests of the samples after hot direct extrusion and heat treatment are presented.

\section{Material Processing}

The studied alloy was prepared from high purity (>99.99 wt.\%) nickel and titanium rods using Balzers VSG10 vacuum induction melting furnace. In order to reduce the carbon contamination of the ingot the high-quality, lowporosity, and high-density graphite crucible and graphite mold were used. The melting process was started when in the furnace $5 \times 10^{-3} \mathrm{~Pa}$ vacuum was obtained. The ingot of $900 \mathrm{~g}$ (Fig. 1) was homogenized in the electrical vacuum furnace at $900{ }^{\circ} \mathrm{C}$ for $48 \mathrm{~h}$ in the vacuum of $2 \times 10^{-5} \mathrm{~Pa}$. After homogenization, the ingot was cut into two parts. One of them was packed in steel pipe and subsequently hot forged and the second one was hot direct extruded using laboratory $1000 \mathrm{kN}$ press equipped with electrical furnace for heating the samples up to $1100^{\circ} \mathrm{C}$ (Fig. 2). The extrusion process was carried out at about $900{ }^{\circ} \mathrm{C}$. As a lubricant $\mathrm{MoS}_{2}$ was used. The extrusion die and the rod obtained after hot direct extrusion is presented on Fig. 3. In the last step, the obtained rod was straightened and thin oxidation layer was removed by machining. The diameter of material was

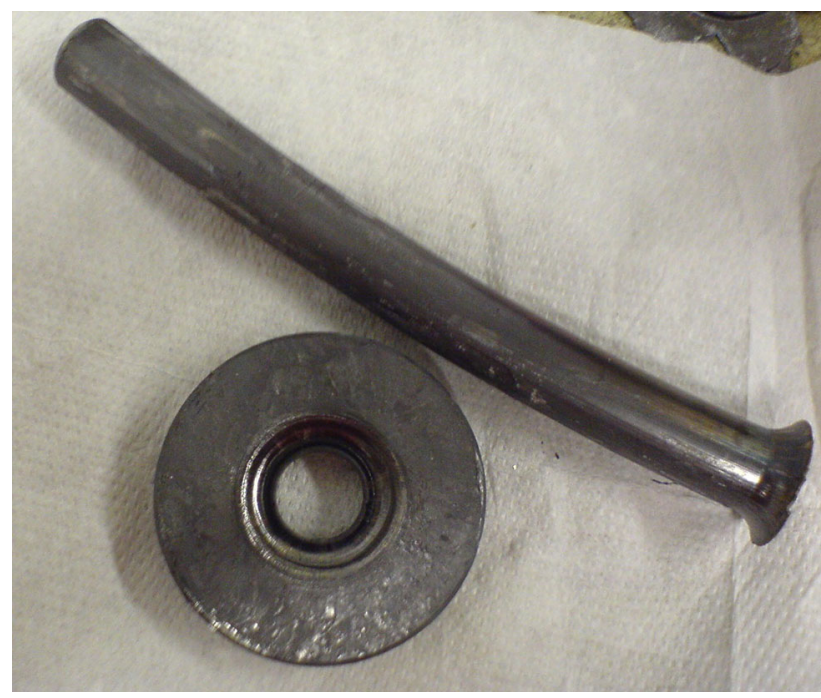

Fig. 3 Extrusion die and a rod after hot direct extrusion

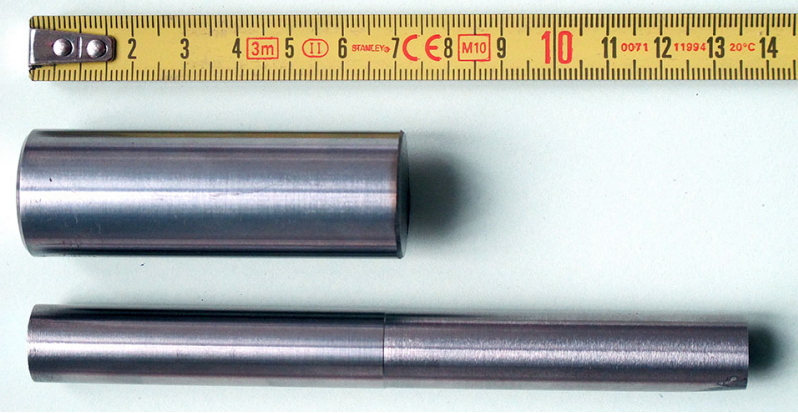

Fig. 4 Billet and extruded rod of studied material after removing of oxide layer. The reduction of diameter is from 25 to $15 \mathrm{~mm}$ 
reduced from 25 to $15 \mathrm{~mm}$ at extrusion ratio 2.34 (Fig. 4). Samples for further studies were cut from the obtained resulting material (Fig. 5).

\section{Experimental}

The $\mathrm{x}$-ray powder diffraction measurements in $2 \theta$ range from $37^{\circ}$ to $47^{\circ}$ were performed on a PANalytical Empyrean

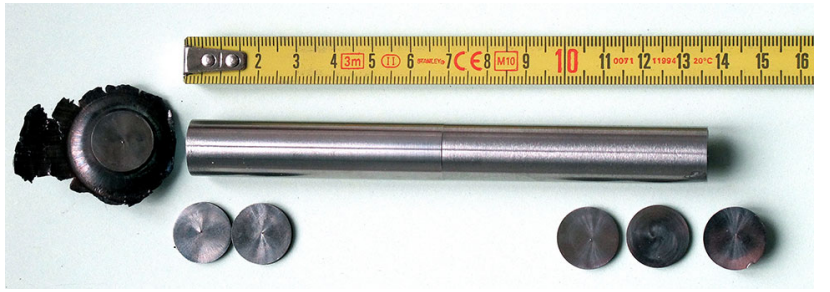

Fig. 5 The straight-extruded NiTi rod after removing the oxide layer by the machining. Cut samples prepared for investigations are also shown

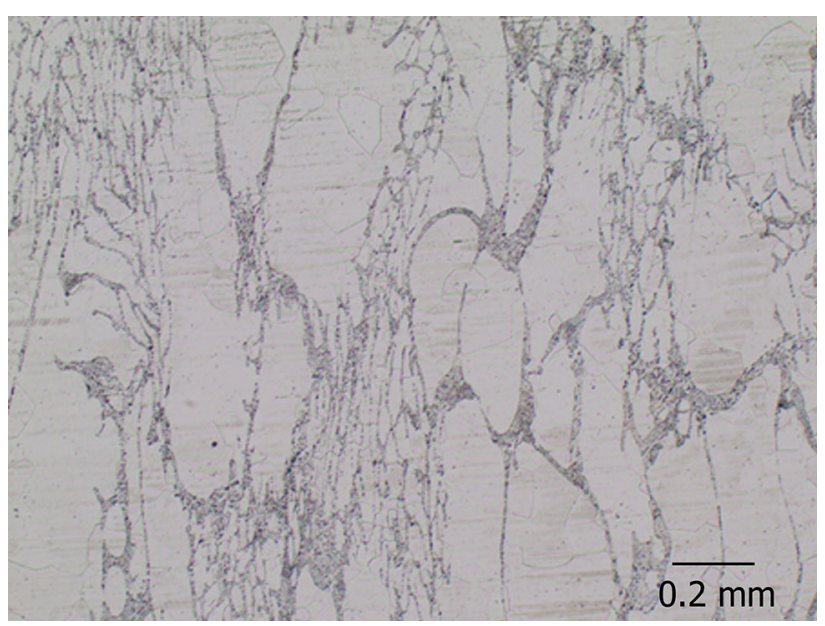

Fig. 6 Microstructure of the extruded alloy-longitudinal crosssection (optical microscopy) diffractometer equipped with Anton Paar TTK450 low-temperature chamber at temperatures from -180 to $250{ }^{\circ} \mathrm{C}$. The measurements were performed with $5{ }^{\circ} \mathrm{C}$ steps resulting heating rate of $0.7^{\circ} \mathrm{C} / \mathrm{min}$. DSC measurements were performed on Mettler Toledo DSC1 calorimeter during cooling and heating at rate of $10{ }^{\circ} \mathrm{C} / \mathrm{min}$. Shape recovery studies were carried out using three-point bending and free recovery ASTM F2082-06 tests with heating rate of $10^{\circ} \mathrm{C} / \mathrm{min}$. The microstructure was studied by optical microscope Olympus GX-51 and JEOL JSM 6480 scanning electron microscope attached with the IXRF energy dispersion detector.

\section{Results}

The optical micrograph of the central part of the extruded rod is shown in Fig. 6. The average grain size is about $50-80 \mu \mathrm{m}$. Significant differences of microstructure have not been observed on cross sections of the central part, head, and foot parts of the rod after extrusion. The images show elongation of some grains after hot extrusion. Additionally,

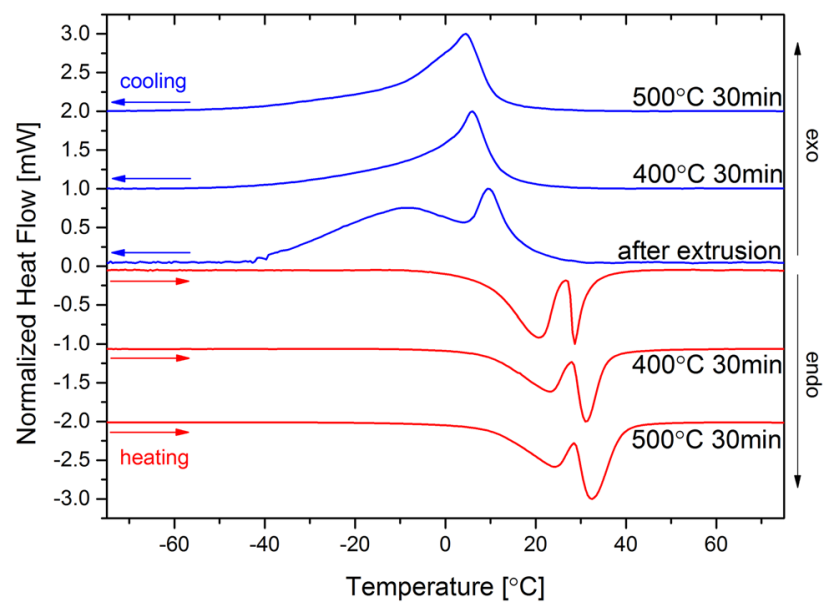

Fig. 8 DSC measurements recorded during cooling and heating cycle for samples after hot extrusion and after further annealing at 400 and $500{ }^{\circ} \mathrm{C}$ for $30 \mathrm{~min}$

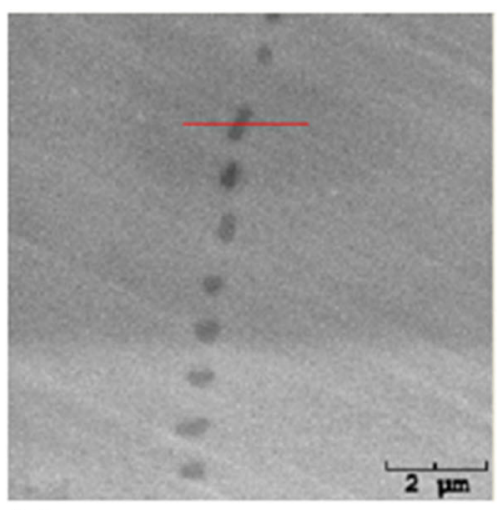

(a)

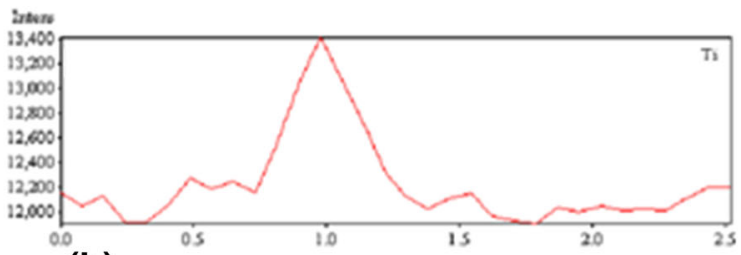

(b)

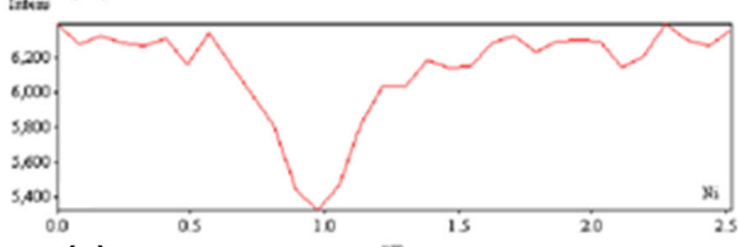

(c)

Fig. 7 SEM image of the eutectics region (a) and the $\mathrm{Ti}$ (b) and $\mathrm{Ni}$ (c) distribution along the red line in (a) 
some eutectics in the grain boundary regions were observed. Since x-ray diffraction did not show any other than B2 phase in these samples, the EDS experiments along the line passing the eutectics region were carried out (Fig. 7). It occurred that the second phase in the eutectics is slightly enriched in titanium and reduced in nickel. However, the changes are very small. Generally, it looks as if during extrusion the sample undergoes dynamical recrystallization. The structure and phase composition of the extruded samples will be the subject of following study.

Performed DSC measurements (Fig. 8) show that the samples after hot direct extrusion and further annealing at 400 and $500{ }^{\circ} \mathrm{C}$ undergo two-step phase transformation during cooling and heating which can be explained by the existence of the $\mathrm{R}$ phase transition. During cooling, the phase transitions are not resolved as clearly as upon heating. From the DSC measurements, it is also visible that the characteristic temperatures shift slightly with increasing annealing temperature. The

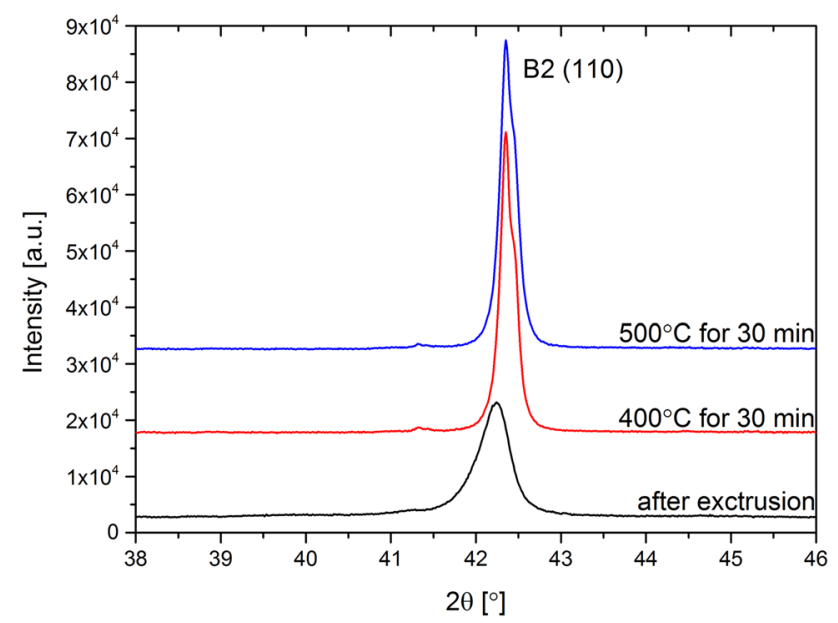

Fig. 9 X-ray powder diffraction patterns recorded at temperature of $35^{\circ} \mathrm{C}$ for samples after hot extrusion and after further annealing at 400 and $500{ }^{\circ} \mathrm{C}$ for $30 \mathrm{~min}$
$M_{\mathrm{s}}$ temperature shifts toward lower values whereas $A_{\mathrm{f}}$ temperature shifts toward higher values increasing the hysteresis loop.

Figure 9 shows $\mathrm{x}$-ray powder diffraction patterns recorded at $35{ }^{\circ} \mathrm{C}$ for samples after extrusion and further annealing at 400 and $500{ }^{\circ} \mathrm{C}$ for $30 \mathrm{~min}$. In all the presented diffraction patterns only $\mathrm{B} 2(110)$ peak is observed which indicates that the studied material below human body temperature has structure of B2 parent phase and is suitable for medical applications.

Color maps of the temperature dependence of LTXRD patterns collected during cooling cycle (Fig. 10) show phase transformations. The $\mathrm{B} 2 \rightarrow \mathrm{R}$ transition is visible as $\mathrm{B}(110)$ peak splitting into $\mathrm{R}(011)$ and $\mathrm{R}(\overline{101})$ peaks. $\mathrm{R} \rightarrow \mathrm{B} 19^{\prime}$ phase transition is visible as appearance of martensite diffraction peaks (marked by $\mathrm{M}$ ) and slowly disappearing of $\mathrm{R}$ phase peak doublet. During heating, the phase transformation occurs also with the existence of the $\mathrm{R}$ phase but the phases coexist in a smaller temperature range. LTXRD measurements have advantage over the DCS measurements because they provide also additional information about phases coexistence during phase transformations (Ref 22). Based on the LTXRD measurements, it is possible to determine the narrow temperature range where only R phase is present during cooling as well as during heating cycle.

LTXRD measurements can be also used in order to obtain the characteristic temperatures of phase transitions. In our studies, the obtained from this method $A_{\mathrm{f}}$ temperatures are lower than the ones from DSC and shape recovery measurements (Table 1). This is caused by different heating rates used in both cases (Ref 23). In the x-ray measurements, the rate of the temperature change was $0.7^{\circ} \mathrm{C} / \mathrm{min}$ while in the DSC and

Table 1 Comparison of $\boldsymbol{A}_{\mathrm{f}}$ temperatures obtained from DSC, shape recovery, and LTXRD measurements

\begin{tabular}{lccc}
\hline & DSC, ${ }^{\circ} \mathbf{C}$ & Shape recovery, ${ }^{\circ} \mathbf{C}$ & XRD, ${ }^{\circ} \mathbf{C}$ \\
\hline After extrusion & 31.9 & 28.5 & 21.5 \\
Annealed at $400{ }^{\circ} \mathrm{C}$ & 35.9 & 35.5 & 22.8 \\
Annealed at $500{ }^{\circ} \mathrm{C}$ & 39.4 & 40.8 & 23.9 \\
\hline
\end{tabular}
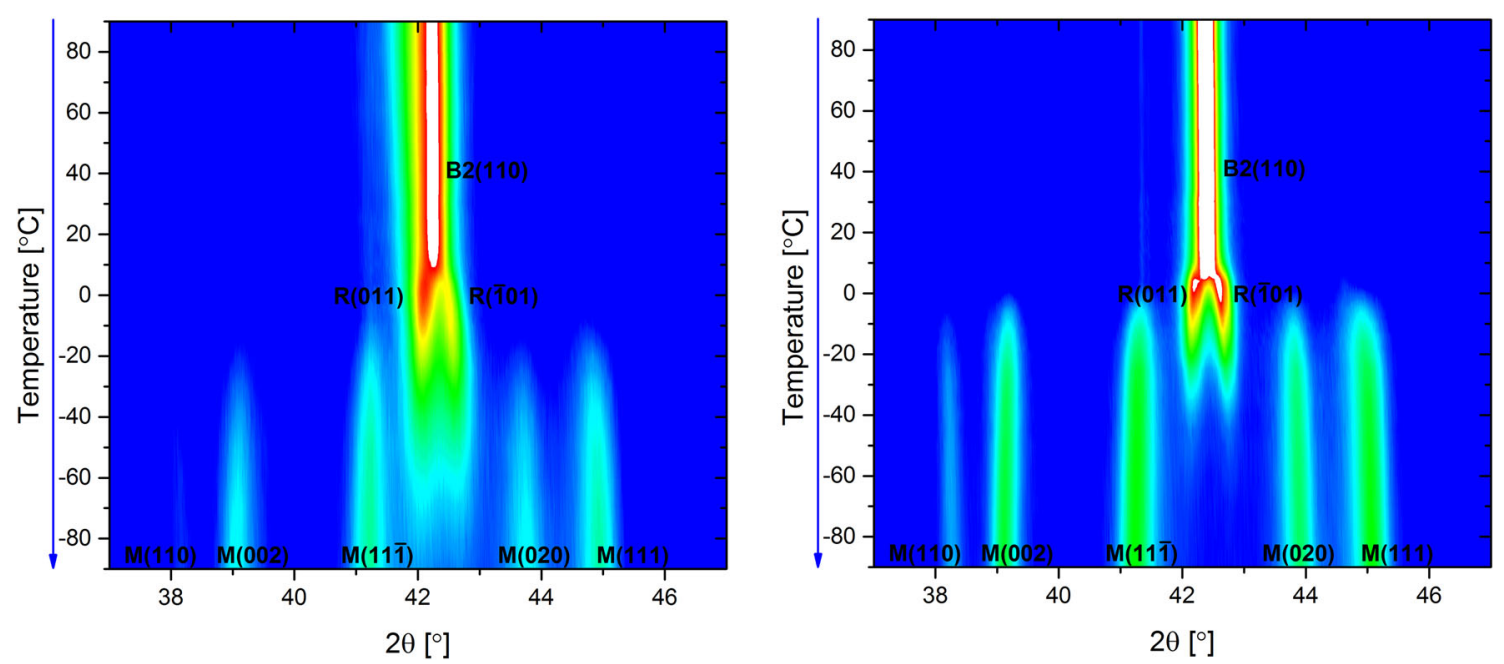

Fig. 10 Color maps of the temperature dependence of LTXRD patterns collected during cooling cycle for sample after hot extrusion (left) and after additional annealing at $500{ }^{\circ} \mathrm{C}$ for $30 \mathrm{~min}$ (right) 


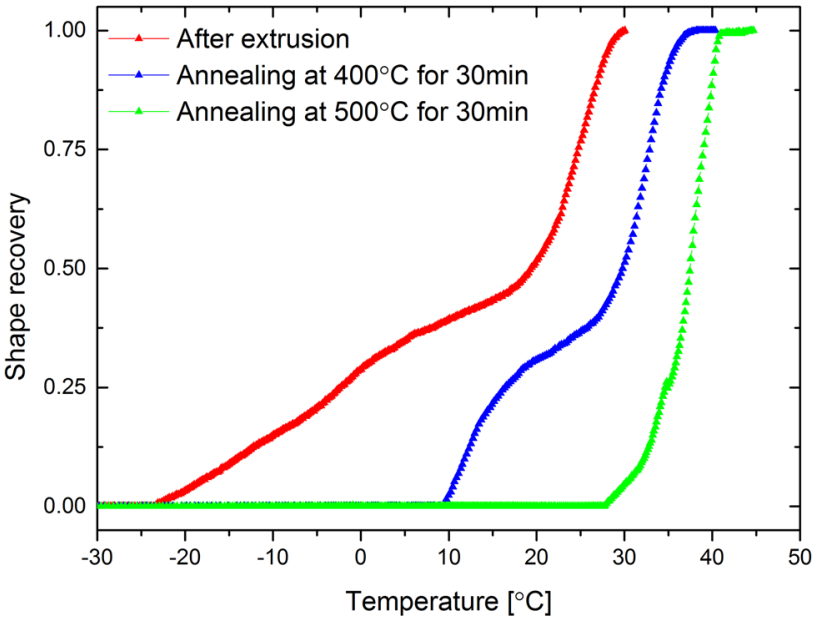

Fig. 11 Shape recovery curves of the studied samples

shape recovery measurements it was $10{ }^{\circ} \mathrm{C} / \mathrm{min}$. High heating/ cooling rates might influence the transformation detection. Therefore, it looks that the x-ray studies in which the temperature changes were slow, are more trustful for the characteristic temperatures determination.

In Fig. 11, shape recovery curves of the studied samples are presented. The obtained curves clearly show that the materials have the desired shape memory properties. With increasing annealing temperature, the characteristic temperatures of the phase transformations shift to the higher values. On the obtained curves, the two-step character of phase transitions is also visible. The obtained characteristic temperatures are in the good agreement with the ones obtained from the x-ray powder diffraction measurements and DSC measurements. More detailed studies of shape recovery in the function of temperature will be done after successive reduction of rod diameter in next process of hot direct extrusion.

\section{Conclusions}

The applied hot direct extrusion process is very effective for rough and fast processing of ingots in order to obtain lessoxidized rods for further plastic working by hot rolling and hot drawing. The proposed laboratory technology allows to obtain NiTi rod with reduction of diameter from 25 to $15 \mathrm{~mm}$ and to preserve of desired shape memory properties of the processed material.

The sample after hot direct extrusion and samples additionally annealed at 400 and $500{ }^{\circ} \mathrm{C}$ for 30 and 60 min were tested. The measurements showed that in all studied samples occurs the reversible transformation $\mathrm{B} 2 \leftrightarrow \mathrm{R} \leftrightarrow \mathrm{B} 19^{\prime}$. Based on the analysis of the diffraction patterns recorded in the function of temperature, the characteristic temperatures of phase transitions were determined. For all studied samples, the $M_{\mathrm{s}}$ temperature is within the range from -5 to $5{ }^{\circ} \mathrm{C}$. During the heating cycle, the transformation to the parent $\mathrm{B} 2$ phase occurs in the temperature range from 20 to $35^{\circ} \mathrm{C}$. Phase transition temperature determined from x-ray diffraction patterns are in good agreement with the temperatures obtained from DSC measurements. With annealing temperature increasing the characteristic temperatures of the phase transformation slightly shift toward higher values. This tendency has been confirmed in the shape recovery measurements. For the studied alloy, the $A_{\mathrm{f}}$ temperature is below human body temperature which makes them useful in medical application. The forged and extruded rods are currently processed by hot rotary forging and hot or cold drawing and annealing to wires of different diameters.

\section{Acknowledgments}

This work was financially supported by the Polish National Science Centre within the frame of the project Nr N N507 296339.

\section{Open Access}

This article is distributed under the terms of the Creative Commons Attribution License which permits any use, distribution, and reproduction in any medium, provided the original author(s) and the source are credited.

\section{References}

1. H. Funakubo, Ed., Shape Memory Alloys, Gordon and Breach Science Publishers, Amsterdam, 1987

2. K. Otsuka and X. Ren, Physical Metalurgy of Ti-Ni-Based Shape Memory Alloys, Prog. Mater. Sci., 2005, 50, p 511-678

3. T.M. Duerig, A. Pelton, and D. Stoeckel, An Overview OD Nitinol Medical Applications, Mater. Sci. Eng. A, 1999, 273-275, p 149-160

4. A.R. Pelton, D. Stoeckel, and T.W. Duerig, Medical Uses of Nitinol, Mater. Sci. Forum, 2000, 327-328, p 63-70

5. L.G. Machado and M.A. Savi, Medical Applications of Shape Memory Alloys, Braz. J. Med. Biol. Res., 2003, 36, p 683-691

6. J. Drugacz, Z. Lekston, K. Januszewski, and H. Morawiec, Use of TiNiCo Shape-Memory Clamps in the Surgical Treatment of Mandibular Fractures, J. Oral Maxillofac. Surg., 1995, 53, p 665-672

7. T. Yoneyama and S. Miyazaki, Ed., Shape Memory Alloys for Biomedical Applications, Woodhead Publishing Limited, Cambridge, 2009

8. Z. Lekston, J. Drugacz, and H. Morawiec, Application of Superelastic NiTi Wires for Mandibular Distraction, Mater. Sci. Eng. A, 2004, 378, p 537-541

9. H. Morawiec, Z. Lekston, K. Kobus, M. Węgrzyn, and J. Drugacz, Superelastic NiTi Springs for Corrective Skull Operations in Children with Craniosyntosis, J. Mater. Sci. Mater. Med., 2007, 18, p 1791-1798

10. Z. Lekston, D. Stróż, and M. Jędrusik-Pawłowska, Preparation and Characterization of Nitinol Bone Staples for Cranio-Maxillofacial Surgery, J. Mater. Eng. Perform., 2012, 21, p 2650-2656

11. S.M. Russell, Nitinol Melting and Fabrication, SMST-2000 Conference Proceedings, S.M. Russel and A. Pelton, Ed., 30 April to 4 May, 2000 (Asilomar), SMST, 2001, p 1-9

12. M.H. Elahinia, M. Hashemi, M. Tabesh, and S.B. Bhaduri, Manufacturing and Processing of NiTi Implants: A Review, Prog. Mater. Sci., 2012, 57, p 911-946

13. C.M. Jackson, H.J. Wagner, and R.J. Wasilewski, 55-Nitinol-The Alloy with a Memory: Its Physical Metallurgy, Properties and Applications. Report NASA-SP 5110, Washington, DC, 1972, p 1-86

14. J. Frenzel, Z. Zhang, K. Neuking, and G. Eggeler, High Quality Vacuum Induction Melting of Small Quantities of NiTi Shape Memory Alloys in Graphite Crucibles, J. Alloys Compd., 2004, 385, p 214-223

15. N. Nayan, C.N. Saikrishna Govind, K. Venkata Ramaiah, S.K. Bhaumik, K. Suseelan Nair, and M.C. Mittal, Vacuum Induction Melting of NiTi Shape Memory Alloys in Graphite Crucible, Mater. Sci. Eng. A, 2007, 465, p 44-48

16. M.H. Wu, Fabrication of Nitinol Materials and Components, SMST2001 Conference Proceedings, Y.Y. Chu and L.C. Zhao, Ed., September 2-6, 2001 (Kunming), SMST-SMM, 2001, p 285-292, Mater. Sci. Forum, 2002, 394-395, p 285-292 
17. K.B. Müller, Hot Extrusion of Nickel-Titanium (Nitinol), SMST-2000 Conference Proceedings, S.M. Russel and A. Pelton, Ed., 30 April to 4 May, 2000 (Asilomar), SMST, 2001, p 43-51

18. A. Tuissi, P. Bassani, A. Mangioni, L. Toia, and F. Butera, Fabrication Process and Characterization of NiTi Wires for Actuators, SMST-2004 Conference Proceedings, M. Mertmann, Ed., 2004, p 501-508

19. K.B. Müller, Extrusion of Nickel-Titanium Alloys Nitinol to Hollow Shapes, J. Mater. Process. Technol., 2001, 111, p 122-126

20. R. Matsui, F. Yoshida, and H. Kyogoku, SMST-2007 Conference Proceedings, S.M. Russel and A. Pelton, Ed., December 3-5, 2007, Tsukuba, Japan SMST, 2007, p 33-38
21. S.M. Quawabah, Effect of Direct Extrusion on the Microstructure, Microhardness, Surface Roughness and Mechanical Characteristics of Cu-Zn-Al Shape Memory Alloy, SMA, Jordan J. Mech. Ind. Eng., 2012, 6(2), p 175-181

22. Z. Lekston and M. Zubko, Low-Temperature XRD Study of Phase Transformations in NiTi and TiNiCo Shape Memory Alloys Used for the Preparation of the Prototypes of Medical Implants, Solid State Phenom., 2013, 203-204, p 125-128

23. K. Nurveren, A. Akdogan, and W. Huang, Evolution of Transformation Characteristics with Heating/Cooling Rate in NiTi Shape Memory Alloys, J. Mater. Process. Technol., 2008, 196, p 129-134 